\title{
Oklahoma's induced seismicity strongly linked to wastewater injection depth
}

\author{
Thea Hincks, ${ }^{1,2}$ Willy Aspinall, ${ }^{1,2,3}$, Roger Cooke ${ }^{4,5}$, Thomas Gernon, ${ }^{6 *}$ \\ ${ }^{1}$ School of Earth Sciences, University of Bristol, BS8 1RJ, UK \\ ${ }^{2}$ Cabot Institute, Royal Fort House, University of Bristol, BS8 1UJ, UK \\ ${ }^{3}$ Aspinall \& Associates, Cleveland House, High Street, Tisbury SP3 6HF, UK \\ ${ }^{4}$ Delft University of Technology, Mekelweg 4, 2628 CD, Delft, The Netherlands \\ ${ }^{5}$ Resources for the Future, 1616 P St NW, Washington DC 20036, USA \\ ${ }^{6}$ Ocean \& Earth Science, University of Southampton, Southampton SO14 3ZH, UK \\ *To whom correspondence should be addressed; E-mail: thomas.gernon@ noc.soton.ac.uk
}

The dramatic rise in Oklahoma seismicity since 2009 is due to wastewater injection. The role of injection depth is an open, complex issue, yet critical for hazard assessment and regulation. We developed an advanced Bayesian Network to model joint conditional dependencies between spatial, operational, and seismicity parameters. We found injection depth relative to crystalline basement most strongly correlates with seismic moment release. The joint effects of depth and volume are critical, as injection rate becomes more influential near the basement interface. Restricting injection depths to 200-500 m above basement could reduce annual seismic moment release by a factor of 1.4-2.8. Our approach enables identification of sub-regions where targeted regulation may mitigate effects of induced earthquakes, aiding operators and regulators in wastewater disposal regions. 
Accepted manuscript; doi: 10.1126/science.aap7911

\section{One sentence summary}

Seismic moment release in Oklahoma is strongly correlated with injection depth relative to the basement.

\section{Main text}

Oklahoma's 900-fold increase in the annual rate of seismicity since 2009 (1) (Fig. S1), makes it the most seismically active region in the contiguous United States. Wastewater disposal via deep injection wells explains the surge in earthquake activity (1-7). In many cases, pressurized fluids migrate from target formations downwards into the crystalline basement $(1,7-10)$, where most earthquakes occur (11-18). The disposed fluids may locally increase pore fluid pressure and reduce the effective stress along faults $(2,9,11)$, resulting in induced seismicity $(2,19)$. In September 2016, a magnitude $\left(M_{w}\right) 5.8$ earthquake centered near Pawnee caused injury and damage to buildings, prompting the immediate suspension of 37 disposal wells (20). The number of damaging earthquakes $(5,6,21)$ resulted in litigation against well operators $(22)$, increased risk to critical infrastructure (23), and considerable financial loss in the reinsurance industry (24).

The escalating seismicity compelled Oklahoma regulators to introduce emergency directives aimed at managing injection (25), informed by an empirical understanding of how seismicity responds to changes in injection rates or volumes $(2,4,6)$. These measures appear to have decreased the earthquake count $\left(M_{w} \geq 3\right)$ in the period $2015(21)$ to present (Fig. S1). Considering the purported strong association between seismicity and oil production in Oklahoma (26), a major driver of this trend could have been abated injection due to relatively low oil prices. However, a case has been made (27) that the probabilities of occurrence of larger magnitude earthquakes are not decreasing as rapidly as other models suggest (1). The total seismic mo- 
Accepted manuscript; doi: 10.1126/science.aap7911

ment release has declined only modestly despite decreased injection volumes (Fig. S1). The ultimate impact of reduced injection may take years to materialize given observed lagging in the response of seismicity levels to injection $(11,27,28)$.

The Oklahoma Corporation Commission (OCC) requires operators to prove their injection does not encounter basement lithologies (29), but debate remains on the precise influence of injection depth. While a study encompassing the wider Central and Eastern US (CEUS) found no significant correlation between proximity to basement and earthquake occurrence (4), other studies suggest that injections near, or within, crystalline basement might increase the likelihood of seismicity locally $(12,30,31)$. Therefore, we need to analyze the joint effects of spatial, operational, geologic and seismicity parameters $(4,19,21)$.

We developed a Bayesian Network (BN) to quantitatively evaluate correlations between well operational parameters, geologic setting, and seismicity, focusing on the 'Oklahoma induced seismicity zone' (5) (Fig. 1). Our BN framework capitalizes on mathematical advances (32) and innovative software, UNINET (33), implemented in R (34). UNINET models joint dependency using continuous data distributions, bypassing the limiting assumptions of discrete approximations (32). Monthly Underground Injection Control (UIC) well data for January 2011 to September 2016 were obtained from OCC (35), including injected volume, pressure, duration of well activity and total well depth. Earthquake location and magnitude data, from the Advanced National Seismic Systems' (ANSS) earthquake catalog, ComCat (36), were used to calculate total seismic moment release. We considered earthquakes of $M_{w} \geq 2$, with a hypocentral depth $<10 \mathrm{~km}$ (Fig. S3), and a hypocenter falling within $20 \mathrm{~km}$ of an injection well (32). We chose this distance based on the documented occurrence of associated earthquake swarms within $10 \mathrm{~km} \mathrm{(37)} \mathrm{to} 20 \mathrm{~km} \mathrm{(3)} \mathrm{of} \mathrm{high-rate} \mathrm{disposal} \mathrm{wells,} \mathrm{supported} \mathrm{by} \mathrm{additional} \mathrm{calculations}$ that indicate strong correlations between injection and moment up to $\sim 20 \mathrm{~km}(32)$. Basement depths at well sites were estimated by spline interpolation $(32,38)$ using 1232 depth records 
Accepted manuscript; doi: 10.1126/science.aap7911

from Oklahoma Geological Survey (39) (Fig. S5).

Over the study period, $>10,000$ active class II UIC wells in Oklahoma (Fig. 1A-B) collectively injected on average $\sim 2.3$ billion barrels of fluid per year via Saltwater Disposal (SWD) and Enhanced Oil Recovery (EOR) (35) (Figs. S1-S2; Table S1). We considered class II injections into the full range of target geologic formations, to capture all potential contributions to induced seismicity (32). Wastewater disposal is particularly intensive within the CambrianOrdovician Arbuckle Group, a sedimentologically and structurally heterogeneous sequence of dolomitized carbonates and breccias $\sim 1.5$ to $2 \mathrm{~km}$ thick (40) throughout most of the study area. Sedimentary cover is hydraulically connected to Precambrian crystalline basement $(1,7-9)$ (Fig. S6) via an extensive fault network $(14,17,41,42)$ (Fig. 1C).

High-rate injection has been linked to increased seismicity (4). However, analysis using BN and regression models indicate that other parameters have an important, but largely unquantified, impact on seismic hazard. We explored correlations between key operational and spatial characteristics and seismicity, comparing a number of network configurations with a simple linear regression (Fig. 2) to determine the most appropriate model (32). We defined nodes for key observables, including well operating parameters (depth, monthly, annual and cumulative injected volume), geologic parameters (distance to basement), and total seismic moment release within $20 \mathrm{~km}$ of the well in the year ahead (Figs. 2A-B) (32)—a standard timescale for operational and seismic hazard forecasts $(5,6,21)$. To improve forecasting for deeper and higher volume wells associated with higher seismicity (Fig. 3, Fig. S7) (32), our models focused on wells $\geq 1 \mathrm{~km}$ deep and cases of monthly injection $>10,000 \mathrm{bbl}$, i.e. those of greater concern to regulators (20). We used UNINET in 'data mining' mode to estimate the set of joint normal copulae (multivariate probability distributions) that most closely represented the input data (32). We used the resulting models to estimate moment release for any given set of operating conditions. 
Accepted manuscript; doi: 10.1126/science.aap7911

The saturated BN (Fig. 2A) (32) gave the most complete representation of the observed data under stationary conditions, outperforming the regression model (in-sample testing, Table S3; Figs. S9-S10). However, the unsaturated BN (Fig. 2B) performed better forecasting ahead under the changing injection regime of 2015-16 (Fig. S1B). This is because rank correlations between volume variables in the saturated BN preserved relationships (associated with increasing injection) that were no longer valid under post-2015 operating conditions.

We used two test datasets for model verification (Fig. S11, Table S3). The first demonstrated operational use of the $\mathrm{BN}$ to forecast future moment release, learning with observations from January 2011-June 2015, and forecasting from July-December 2015. The second test used $90 \%$ of the full dataset for learning (January 2011-December 2015, randomly sampled), and the remaining 10\% for verification (Fig. S11) (32). We compared forecast results using the BN and regression models (Fig. 2, Figs. S11-S12, Table S6), and found that in both cases the BN gave the best performance.

The spatial distribution of earthquakes (Fig. 1B-C; Fig. S2) implies important underlying geologic characteristics influencing seismicity. The BN cannot explicitly represent these characteristics due to the variability and paucity of geologic data at relevant depths and resolution across the region. To address this issue, we applied the models iteratively to identify where (spatially) they systematically under- or over-forecast, due to latent features outside the scope of the model. We used both $\mathrm{BN}$ and regression models to estimate seismic moment for a subset of the training data, and used the forecast error to compute a 'geospatial correction' map-a proxy for unobserved geologic data (32) (Fig. S8). We repeated the learning step with the training data using the geospatial correction as an additional input node. We used this revised network (Fig. 2) for final forecast verification (Figs. S10, S12 and S13) (32).

The geospatial correction shows the strongest (negative) correlation $(-0.55)$ with annual moment release (Fig. 2C), supporting the observation that lithologic (9) and fault network char- 
Accepted manuscript; doi: 10.1126/science.aap7911

acteristics $(14,16-18)$ collectively play a critical role in determining susceptibility to induced seismicity. Root mean squared errors (RMSE), mean absolute errors (MAE) and median average deviation (MAD) for the $\mathrm{BN}$ and regression models with and without the geospatial correction node show the improvement in forecast skill resulting from this additional step (Table S6, Test 2). This degree of improvement suggests the geospatial correction effectively characterizes the impact of important, but unobservable (latent) factors. It could additionally prove valuable in mapping spatial variation in induced earthquake hazard (21).

Our analysis with UNINET shows that distance to the basement interface is more strongly correlated (-0.34) with annual seismic moment release than injected volume, and cumulative injected volume has a stronger correlation $(+0.26)$ with annual seismic moment release than annual $(+0.20)$ or monthly (+0.18) volume (Fig. 2C, empirical rank correlations). However, we expect these volume correlations to change with time due to the effects of regulation, marketdriven changes in oil production and associated disposal, and time lags between injection and induced seismicity. For example, cumulative volume will become less well correlated with annual moment if the current trend of reduced seismicity continues (Fig. S1A).

UNINET uses joint normal copulae $(32,33)$. As several input distributions are highly skewed, and seismic moment is censored (due to catalog incompleteness for $M_{w}<2.5$; Fig. S4), the normal copula cannot perfectly represent the data. We see this in the difference between the empirical and BN unconditional rank correlations (Table S5) and cumulative distribution functions (CDFs; Fig. 2, Figs. S12-S13). However, calculations suggest that using optimal copulae would yield only a small improvement, negated by greatly increased computational complexity (32). The asymmetry of the data also means that a linear model will not perform as well as the BN (e.g. Figs. 2D-E).

We demonstrate how the BN could be used to quantify the expected impact of UIC regulations with three applied examples. We can (i) reduce injection depth by a fixed amount (to 
Accepted manuscript; doi: 10.1126/science.aap7911

simulate well plug back (29) or optimal depth of a new well), (ii) cap injection volume according to imposed regulatory limits $(25,43)$, and (iii) restrict injection depth in the Oklahoma induced seismicity zone, by enforcing a minimum permissible distance above the basement interface. We intend these examples as demonstrations of how the $\mathrm{BN}$ could be used in practice. Before using this approach to inform operational or regulatory practices, further detailed simulations would be required accounting for local-scale susceptibility to induced seismicity.

For a subset (10\%) of well records (Fig. S11), we reduced well depth by $1000 \mathrm{~m}$, and the resulting 'test data' were used to produce a set of revised forecasts for annual moment release. We calculated the change in mean moment for each individual case due to the change in depth (Fig. 4). For above-basement wells, raising the well by $1000 \mathrm{~m}$ shifted injection further from the basement (shallower), and led to a reduction in seismic moment release. We found the greatest reduction in wells injecting higher volumes (Fig. 4A). Conversely, increasing depth to inject closer to (or into) the basement led to an increase in seismic moment release (Fig. S14).

To model the potential impact of regulating volume, we applied a daily limit of $15,000 \mathrm{bbls}$ per well as imposed by Oklahoma regulators (25), similar to the Kansas 16,000 bbl/day limit for areas of "seismic concern" (43). We applied this limit to the full dataset, and used the revised monthly injections to recalculate annual and cumulative volumes for each well (32). We then used the BN to simulate the revised annual moment release for all individual monthly well records with reduced injection (Fig. 4B).

As expected, our simulations showed that wells subjected to the largest drop in monthly and annual injected volume yielded the greatest reduction in moment release (Fig. 4B). We found a small number of exceptions where large changes in mean annual moment were predicted for wells with relatively low annual injection rates (Fig. 4B). These cases largely corresponded to wells injecting close to the basement (Fig. S15), where more modest changes in injection volume can yield proportionally larger decreases in moment (Fig. 4). This demonstrates the 
Accepted manuscript; doi: 10.1126/science.aap7911

importance of quantifying the joint effect of operational parameters (depth, cumulative and injection rates) on future seismicity levels.

We performed a final set of simulations to quantify the statewide impact of depth restriction, using depth limits of (i) $200 \mathrm{~m}$ and (ii) $500 \mathrm{~m}$ above basement, wherever this could be practically applied. Using well records for December 2015 to predict annual moment release in the year ahead, we found an indicative (mean) reduction in total annual moment release for the Oklahoma induced seismicity zone of a factor of $\sim 1.4$ for the $200 \mathrm{~m}$ limit, and a factor of $\sim 2.8$ for the 500 m limit (32).

A distinct advantage of the $\mathrm{BN}$ is the ability to update the model, and produce revised forecasts as data become available. For example, using newly released (September 2017) OCC injection data (35), we tested BN forecasting for 2016, firstly using the model as developed above (Fig. S16), and secondly using an updated geospatial correction and moving window for learning, which (by partially accounting for temporal changes in the system) improves performance (Fig. S17-S18) (32). The empirical and unconditional BN rank correlations (Table S7) computed using the complete updated dataset are not considerably different from those for 2011-15 (Table S5), lending credence to the basic model.

Our results indicate that seismic moment release in Oklahoma is strongly correlated with injection proximity to crystalline basement (Figs. 3 and 4A; Fig. S7), corroborating previous hypotheses $(30,31)$, but contrary to observations encompassing the CEUS (4). We attribute this disparity to scale dependence (19). In Oklahoma, the permeability structure of the Arbuckle Group permits downward fluid migration into crystalline basement $(1,9)$, causing reactivation of optimally oriented strike-slip faults $(14,16-18)$. On a continental scale, lithologic and structural heterogeneity and concomitant stress-field variations could obscure any association between depth and seismicity, as some lithologies are more susceptible to earthquakes (9) (Fig. S6); e.g. where fracture flow causes localized pore fluid pressure increases, allowing rupture along 
Accepted manuscript; doi: 10.1126/science.aap7911

critically stressed faults (9). Regions of relatively high permeability basement in other parts of the CEUS will conceivably permit greater pore fluid diffusion and pressure release, inhibiting earthquakes (9). Induced seismicity is also controlled by local hydrogeologic conditions (30), and the location, scale and orientation of critically stressed faults—all unique aspects of the geotectonic setting. This highlights the importance of local-scale assessments.

Our Oklahoma assessment exploited a 6-year record of fluid injection to develop a comprehensive understanding of the controls on induced seismicity. The two-stage BN quantifies the joint effects of operational parameters and latent spatial features on seismic moment release, facilitates regular model updating, and offers improved forecast performance compared to traditional linear models. This approach has important implications for statewide assessments and regulatory decision-making under geologic uncertainty (note the Pawnee $(16,18,44)$, Cushing (44), Prague $(11,14)$ and Fairview (45) earthquakes occurred on previously unrecognized faults or splays). Our framework allows regulatory actions to be evaluated on a rational, quantitative basis in terms of seismic effects. The model could be used to identify evolving vulnerability, complimenting zoned seismic hazard forecasts of the USGS (21), and provide a basis for targeted management of induced seismicity in Oklahoma and other wastewater disposal regions. We welcome the support of researchers, operators, regulators and policy makers, in updating and extending our model.

\section{References and Notes}

1. C. Langenbruch, M. D. Zoback, How will induced seismicity in Oklahoma respond to decreased saltwater injection rates?, Science Advances 2 (2016).

2. W. L. Ellsworth, Injection-induced earthquakes, Science 341 (2013). 
Accepted manuscript; doi: 10.1126/science.aap7911

3. K. M. Keranen, M. Weingarten, G. A. Abers, B. A. Bekins, S. Ge, Sharp increase in central Oklahoma seismicity since 2008 induced by massive wastewater injection, Science 345, 448 (2014).

4. M. Weingarten, S. Ge, J. W. Godt, B. A. Bekins, J. L. Rubinstein, High-rate injection is associated with the increase in U.S. mid-continent seismicity, Science 348, 1336 (2015).

5. M. D. Petersen, et al., Incorporating induced seismicity in the 2014 United States national seismic hazard model—results of 2014 workshop and sensitivity studies, Tech. Rep. 2015 1070, U. S. Geological Survey (2015).

6. M. D. Petersen, et al., 2016 one-year seismic hazard forecast for the Central and Eastern United States from induced and natural earthquakes, Tech. rep., U. S. Geological Survey, Reston, VA (2016).

7. F. R. Walsh, M. D. Zoback, Oklahoma's recent earthquakes and saltwater disposal, Science Advances 1 (2015).

8. P. O. Ogwari, S. P. Horton, Numerical model of pore-pressure diffusion associated with the initiation of the 2010-2011 Guy-Greenbrier, Arkansas earthquakes, Geofluids 16, 954 (2016).

9. A. K. Shah, G. R. Keller, Geologic influence on induced seismicity: Constraints from potential field data in Oklahoma, Geophysical Research Letters 44, 152 (2017). 2016 GL071808.

10. N. D. McMahon, R. C. Aster, W. L. Yeck, D. E. McNamara, H. M. Benz, Spatio-temporal evolution of the 2011 Prague, Oklahoma aftershock sequence revealed using subspace detection and relocation, Geophysical Research Letters 44, 7149 (2017). 
Accepted manuscript; doi: 10.1126/science.aap7911

11. K. M. Keranen, H. M. Savage, G. A. Abers, E. S. Cochran, Potentially induced earthquakes in Oklahoma, USA: Links between wastewater injection and the $2011 \mathrm{Mw} 5.7$ earthquake sequence, Geology 41, 699 (2013).

12. W.-Y. Kim, Induced seismicity associated with fluid injection into a deep well in Youngstown, Ohio, Journal of Geophysical Research: Solid Earth 118, 3506 (2013).

13. S. Horton, Disposal of hydrofracking waste fluid by injection into subsurface aquifers triggers earthquake swarm in Central Arkansas with potential for damaging earthquake, Seismological Research Letters 83, 250 (2012).

14. D. E. McNamara, et al., Earthquake hypocenters and focal mechanisms in central Oklahoma reveal a complex system of reactivated subsurface strike-slip faulting, Geophysical Research Letters 42, 2742 (2015).

15. M. Shirzaei, W. L. Ellsworth, K. F. Tiampo, P. J. González, M. Manga, Surface uplift and time-dependent seismic hazard due to fluid injection in eastern Texas, Science 353, 1416 (2016).

16. E. J. Fielding, S. S. Sangha, D. P. S. Bekaert, S. V. Samsonov, J. C. Chang, Surface deformation of North-Central Oklahoma related to the $2016 \mathrm{M}_{w} 5.8$ Pawnee earthquake from SAR interferometry time series, Seismological Research Letters 88, 971 (2017).

17. M. Schoenball, W. L. Ellsworth, Waveform-relocated earthquake catalog for Oklahoma and Southern Kansas illuminates the regional fault network, Seismological Research Letters $\mathbf{8 8}$, 1252 (2017).

18. X. Chen, et al., The Pawnee earthquake as a result of the interplay among injection, faults and foreshocks, Scientific Reports 7, 4945 (2017). 
Accepted manuscript; doi: 10.1126/science.aap7911

19. National Research Council (U.S.), Induced seismicity potential in energy technologies (National Academy of Sciences, Washington, DC 20001, 2013).

20. Oklahoma Corporation Commission Earthquake Response Summary, 18 Nov 2016; http: / / www. occeweb.com/News / 2016/11-23-16EARTHQUAKE응 20ACTION2 OSUMMARY . pdf (2016).

21. M. D. Petersen, et al., 2017 one-year seismic-hazard forecast for the Central and Eastern United States from induced and natural earthquakes, Seismological Research Letters 88, 772 (2017).

22. Sierra Club v. Chesapeake Operating LLC et al., F. Supp. 3d, WL 1287546 (W.D. Okla. 2017).

23. D. E. McNamara, et al., Reactivated faulting near Cushing, Oklahoma: Increased potential for a triggered earthquake in an area of United States strategic infrastructure, Geophysical Research Letters 42, 8328 (2015).

24. S. Barrett, The link between hydrofracking, wastewater injection and earthquakes: key issues for re/insurers, Tech. rep., Swiss Reinsurance (2016). http://www.swissre.com/library/2016_08_link_hydrofracking_ wastewater_injection_earthquakes_key_issues_reinsurers.html.

25. Oklahoma Corporation Commission, Central Oklahoma Regional Volume Reduction Plan and Expansion of Area of Interest; www.occeweb.com/News/2016/ 03-07-16ADVISORY-AOI , 20VOLUME $\div 2$ OREDUCTION.pdf (2016).

26. M. van der Baan, F. J. Calixto, Human-induced seismicity and large-scale hydrocarbon production in the USA and Canada, Geochemistry, Geophysics, Geosystems 18, 2467 (2017). 
Accepted manuscript; doi: 10.1126/science.aap7911

27. T. H. W. Goebel, J. I. Walter, K. Murray, E. E. Brodsky, Comment on "How will induced seismicity in Oklahoma respond to decreased saltwater injection rates?” by C. Langenbruch and M. D. Zoback, Science Advances 3, 1 (2017).

28. A. J. Barbour, J. H. Norbeck, J. L. Rubinstein, The effects of varying injection rates in Osage County, Oklahoma, on the $2016 \mathrm{M}_{w} 5.8$ Pawnee earthquake, Seismological Research Letters 88, 1040 (2017).

29. Oklahoma Corporation Commission directive, http://occeweb.com/News/ DIRECTIVE-2.pdf (2015).

30. Y. Zhang, et al., Hydrogeologic controls on induced seismicity in crystalline basement rocks due to fluid injection into basal reservoirs, Groundwater 51, 525 (2013).

31. B. S. Currie, M. Brudzinski, R. Skoumal, Geological Society of America Abstracts with Programs (2016), vol. 48.

32. Materials and Methods are available as supplementary materials on Science Online.

33. Uninet software designed by the Risk and Environmental Modeling group, Delft University of Technology, developed by Dan Ababei, Lighttwist Software; www . lighttwist . net/wp/uninet.

34. The R Project for Statistical Computing; https : / / cran.r-project.org/.

35. Oklahoma Corporation Commission, UIC well data from http://www. occeweb. com/og/ogdatafiles2.htm.

36. ANSS Comprehensive Earthquake Catalog (ComCat), U.S. Geological Survey, https: //earthquake.usgs.gov/data/comcat/; accessed 08 March 2017. 
Accepted manuscript; doi: 10.1126/science.aap7911

37. A. McGarr, A. J. Barbour, Wastewater disposal and the earthquake sequences during 2016 near Fairview, Pawnee, and Cushing, Oklahoma, Geophysical Research Letters 44, 9330 (2017).

38. QGIS Development Team. QGIS Geographic Information System, http://qgis.org (2016).

39. J. Campbell, J. Weber, Wells drilled to basement in Oklahoma, Tech. Rep. 2006-1, Oklahoma Geological Survey, http: / /ogs .ou .edu/docs/specialpublications / SP 2006-1.pdf (2006).

40. E. K. Franseen, A review of Arbuckle Group strata in Kansas from a sedimentologic perspective: Insights for future research from past and recent studies, Kansas Geological Survey, Open-file Report 1999-49 75, 68 (2000).

41. R. A. Northcutt, J. A. Campbell, Geologic Provinces of Oklahoma (Springer Netherlands, Dordrecht, 1998), pp. 29-37.

42. S. Marsh, A. Holland, Comprehensive fault database and interpretive fault map of Oklahoma, Tech. Rep. OF2-2016, Oklahoma Geological Survey, The University of Oklahoma, Norman, OK 73019 (2016).

43. Kansas Corporation Commission, Second Order Reducing Saltwater Injection Rates; http://www.kcc.state.ks.us/pi/press/16-11.htm (2016).

44. W. L. Yeck, et al., Oklahoma experiences largest earthquake during ongoing regional wastewater injection hazard mitigation efforts, Geophysical Research Letters 44, 711 (2017). 
Accepted manuscript; doi: 10.1126/science.aap7911

45. W. L. Yeck, et al., Far-field pressurization likely caused one of the largest injection induced earthquakes by reactivating a large preexisting basement fault structure, Geophysical Research Letters 43, 10,198 (2016).

46. A. M. Hanea, D. Kurowicka, R. M. Cooke, Hybrid method for quantifying and analyzing Bayesian belief nets, Quality and Reliability Engineering International 22, 709 (2006).

47. D. Kurowicka, R. Cooke, Modern Statistical and Mathematical Methods in Reliability, A. Wilson, N. Limnios, S. Keller-McNulty, Y. Armijo, eds. (World Scientific Publishing Co., 2005), pp. 309-323.

48. S. Wiemer, M. Wyss, Minimum magnitude of completeness in earthquake catalogs: Examples from Alaska, the Western United States, and Japan, Bulletin of the Seismological Society of America 90, 859 (2000).

49. Rcomcat library for searching ANSS ComCat comprehensive earthquake catalog; https : //github.com/usgs/rcomcat.

50. S. D. Davis, C. Frohlich, Did (or will) fluid injection cause earthquakes? - Criteria for a rational assessment, Seismological Research Letters 64, 207 (1993).

51. A. Frankel, Mapping seismic hazard in the Central and Eastern United States, Seismological Research Letters 66, 8 (1995).

52. J. Pearl, Causality: Models, Reasoning and Inference (Cambridge University Press, 2009), second edn.

53. The $\mathrm{R}$ Project for Statistical Computing VineCopula package; https://cran. r-project.org/web/packages/VineCopula/VineCopula.pdf. 
Accepted manuscript; doi: 10.1126/science.aap7911

54. R. M. Cooke, H. Joe, B. Chang, Vine regression, Resources for the Future Discussion Paper pp. 15-52 (2015). 
Accepted manuscript; doi: 10.1126/science.aap7911

\section{Figure Captions}

Figure 1: Wastewater injection and seismicity in Oklahoma $\mid$ (A). Map showing the surface expression of key geologic provinces of Oklahoma (41) and class II UIC wells (35) (related to oil and gas production). Black polygon defines the 'Oklahoma induced seismicity zone' delineated by the USGS (5). (B) Map showing total injected volume (bbl) for 2011-2015 (30 km Gaussian kernel density). Symbols denote locations of earthquakes over this period, including the 5 November 2011 Prague $(7,10,11)$ and 3 September 2016 Pawnee $(18,21,28,44)$ events. (C) Map showing total seismic moment release 2011-2016 (20 km Gaussian kernel density), with mapped faults in the sedimentary cover including the Nemaha uplift (arrow) also shown (42) (note this does not include all large-scale basement structures (17)). Yearly injection volumes and seismic moment release are shown in Fig. S2.

Figure 2: BN structure, unconditional rank correlation coefficients, and cumulative distribution functions (CDFs) for Test $2 \mid$ (A) the saturated network and (B) the unsaturated network. Arcs denote influence between nodes. (C) Unconditional rank correlation coefficients for all nodes with $\log _{10}$ annual moment release (empirical data and BNs). This is a measure of the strength of influence of each observable on the node of interest (moment release). The BN uses joint normal copulae to represent the empirical data-the closer the values in the $\mathrm{BN}$ rank correlation matrix are to the empirical rank correlation matrix the better the model approximates the data (matrix determinants can also be compared). Full correlation matrices are provided in Table S5. (D \& E) CDFs of $\log _{10}$ annual moment release for the BN forecast (mean and median estimate), linear regression model, and empirical data for (D) saturated BN, and (E) unsaturated BN. This shows how closely the model output distribution matches the observations. Results are shown for Test 2 - learning using $90 \%$ of the observations, testing with the remaining $10 \%$ 
Accepted manuscript; doi: 10.1126/science.aap7911

(see Fig. S11).

Figure 3: Probability distributions for well depth and distance to basement using $\mathrm{BN}$ inputs for January 2011 to December 2015 (wells $\geq 1 \mathrm{~km}$ deep and injection records $>10,000$ bbl/month) $\mid$ Probability density for (A) well depth below surface; (B) depth relative to basement, and (C) distance to basement; identifying (i) cases with low or no seismic activity ( $\log _{10}$ moment in 1 year $\leq 13$; shaded blue) and (ii) cases with relatively high seismic activity ( $\log _{10}$ moment in 1 year $\geq 15$; shaded pink). This shows that wells drilled closer to the basement are associated with higher seismic moment release. Distributions for injection volume are shown in Fig. S7.

Figure 4: Simulated impact of raising the injection well level or capping monthly injection volume $\mid$ (A). For a subset of records, well depth was reduced by $1 \mathrm{~km}$ and used to generate revised estimates for annual moment release using the BN (colored points) and linear regression models (black points). The plot shows change in annual moment versus original well depth, and predicts the greatest reduction in moment release for wells initially closest to the basement interface. The joint effect of cumulative volume is also seen-wells with higher cumulative injections are expected to experience proportionally greater moment reduction. (B). Predicted change in mean annual moment resulting from a regulatory limit of 15,000 bbl/day (450,000 bbl/month) versus monthly injection with no cap. This plot shows cases of high injection only (where the limit is applied). Points are colored by total reduction in annual volume to illustrate the importance of maintaining injection limits over time. Inset: CDFs for moment release (BN mean estimates) show the overall effect on all high volume wells. 
Accepted manuscript; doi: 10.1126/science.aap7911

\section{Acknowledgements}

T.H. and W.A. were supported in part by the CREDIBLE consortium (UK NERC Grant NE/J 017299/1). W.A. received support in part from Risk Management Solutions (RMS) for a conceptual study associated with induced seismicity attribution. Dan Ababei at LightTwist Software provided invaluable assistance with UNINET software and scripting (available to download at http://www.lighttwist.net/wp/uninet). The study utilized UIC injection well data obtained from the Oklahoma Corporation Commission (http://www.occeweb.com/), and earthquake data from the USGS AMSS Comprehensive Catalog (https://earthquake.usgs.gov/data/comcat/). Input data are provided in the Supplementary Materials on Science Online. We acknowledge helpful discussions with Robert Muir-Wood (RMS, London) and R.J. Briggs (formerly Praedicat Inc., CA). Author contributions: W.A. and T.H. conceived the research. T.H. performed the modeling, analyzed and refined the BN. W.A. provided seismological interpretation. T.G. performed geologic interpretation, coordinated and wrote the paper. R.C. provided support with statistical analysis and performed additional UNINET tests. All authors contributed to the interpretation, discussion and writing.

\section{Supplementary Materials}

www.sciencemag.org/content/

Materials and Methods

Figs. S1 to S18

Tables S1 to S7

Supplementary Data File S1 (aap7911_s1.csv)

References (46-54) 
A

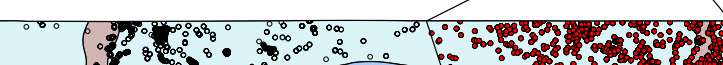

$\square$ USGS induced seismicity zon

- All UIC wells (2011-2015)

- UIC wells in BN analysis

Geological Provinces

$\square$ Detatchment uplift

Basement-rooted uplift

Shallow basin or shelf

Deep basin

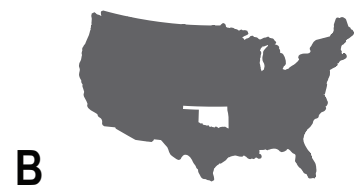

\begin{tabular}{llll}
50 & 0 & $50 \quad 10$ \\
\hline $\mathbf{R}$
\end{tabular}

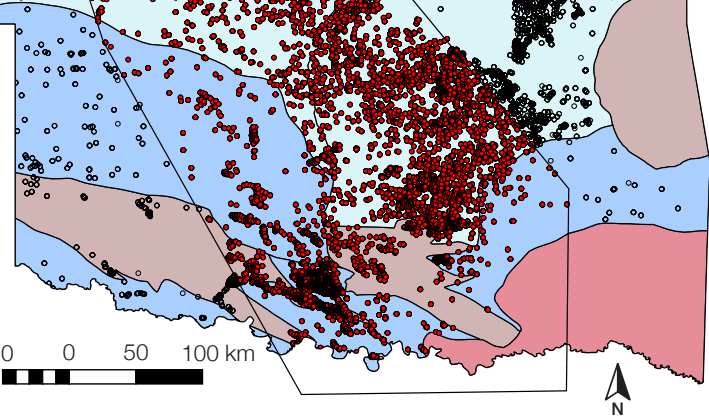

Injected vol. (bbl) Earthquakes

\begin{tabular}{|c|c|}
\hline$\square 10^{4}$ & . $2-3$ \\
\hline$\square 10^{5}$ & $3-4$ \\
\hline$\square 10^{6}$ & 项 4-4.5 \\
\hline $\begin{array}{r}10^{7} \\
110^{8}\end{array}$ & 放 4.5-5 \\
\hline $2 \times 10^{9}$ & క $5-5.5$ \\
\hline
\end{tabular}

$50 \quad 0 \quad 50 \quad 100 \mathrm{~km}$

प्ता

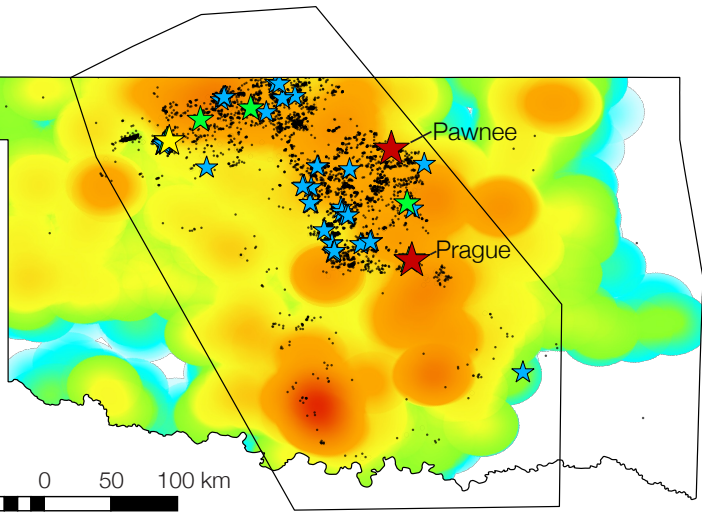

c

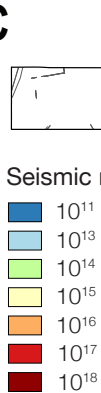

$50 \quad 0 \quad 50 \quad 100 \mathrm{~km}$

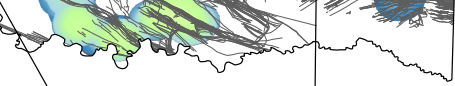




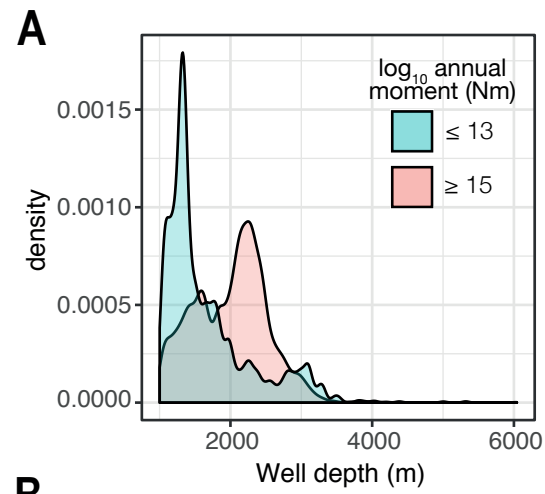

B

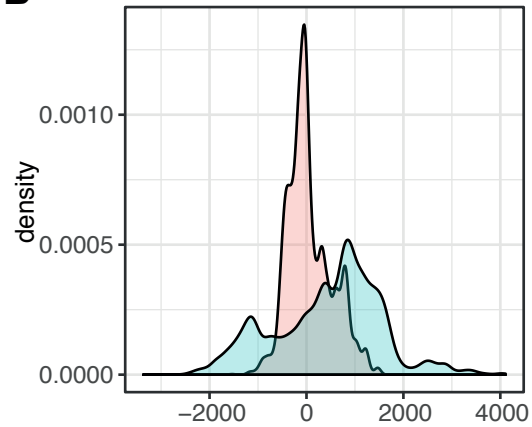

Depth relative to basement $(\mathrm{m})$

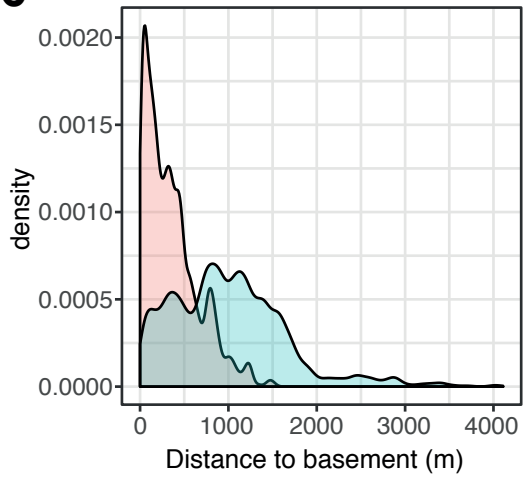




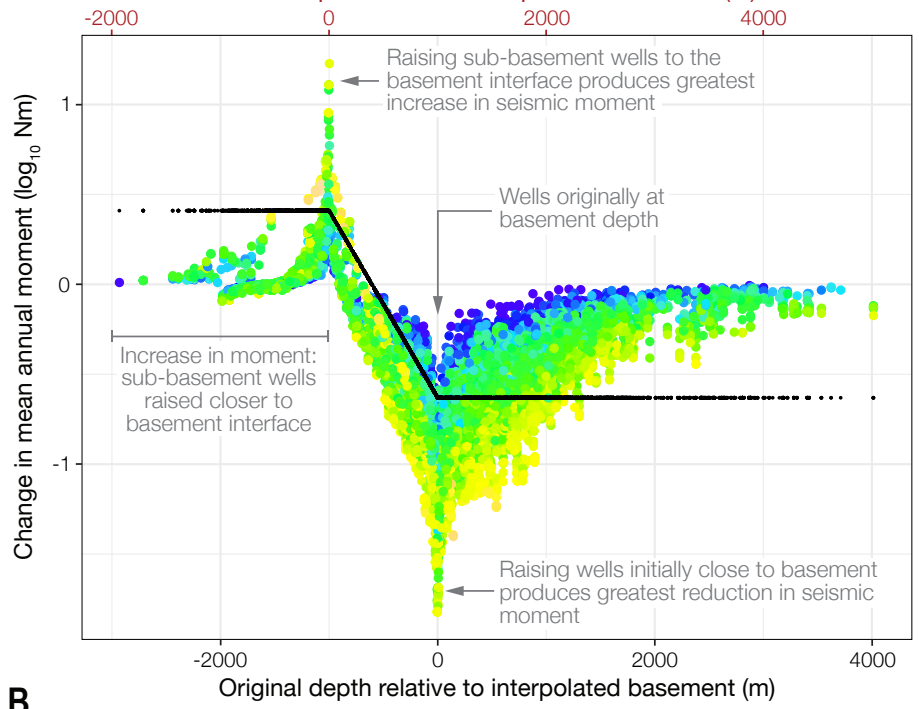

Cumulative volume (bbl)

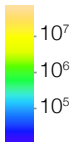

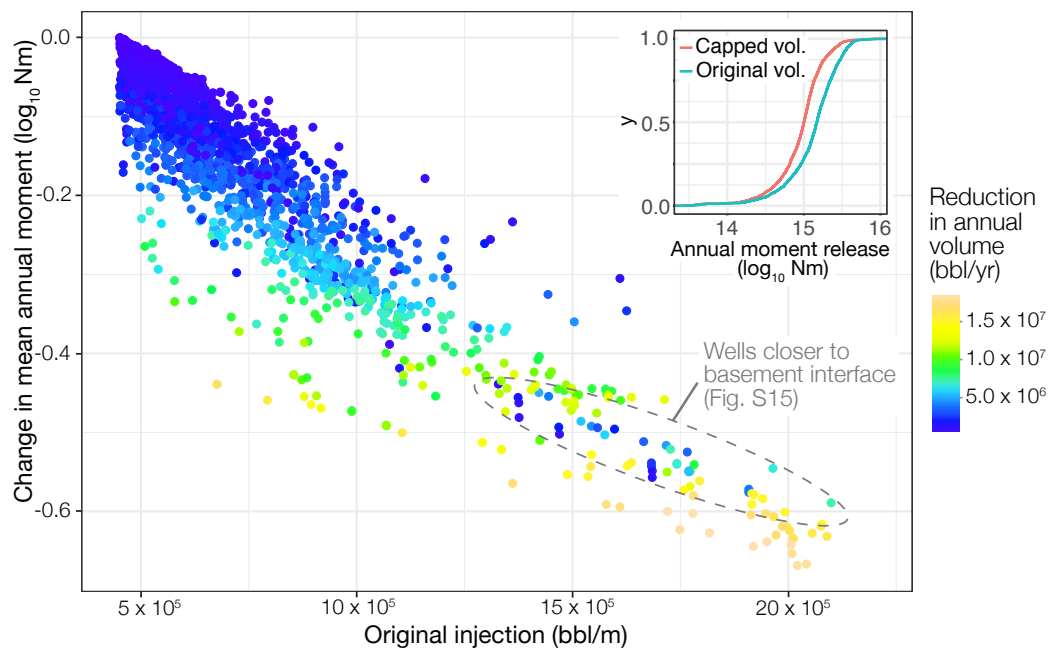

